\title{
Downregulation of epidermal growth factor receptor family receptors and ligands in a mutant K-ras group of patients with colorectal cancer
}

\author{
TOMOKO NAGAOKA ${ }^{1,2}$, KAZUTAKA KITAURA $^{2}$, YUKINAGA MIYATA $^{1,2}$, KENICHI KUMAGAI $^{1,2}$, \\ GORO KANEDA $^{3}$, HIDEKI KANAZAWA ${ }^{3}$, SATSUKI SUZUKI ${ }^{4}$, YOSHIKI HAMADA ${ }^{1}$ and RYUJI SUZUKI ${ }^{2}$ \\ ${ }^{1}$ Department of Oral and Maxillofacial Surgery, School of Dental Medicine, Tsurumi University, \\ Tsurumi-ku, Yokohama 230-8501; ${ }^{2}$ Department of Rheumatology and Clinical Immunology, \\ Clinical Research Center for Rheumatology and Allergy, Sagamihara National Hospital, National Hospital Organization; \\ ${ }^{3}$ Department of Surgery Sagamihara National Hospital, National Hospital Organization, Sagamihara, Kanagawa 252-0392; \\ ${ }^{4}$ Section of Biological Science, Research Center for Odontology, Nippon Dental University, \\ School of Dentistry, Chiyoda-ku, Tokyo 102-0071, Japan
}

Received December 8, 2014; Accepted September 3, 2015

DOI: $10.3892 / \mathrm{mmr} .2016 .4951$

\begin{abstract}
The present study investigated the expression profiles of the epidermal growth factor receptor (EGFR) family, which consists of four transmembrane tyrosine kinase receptors and their eight ligands, in 122 patients with colorectal cancer (CRC) using reverse transcription-quantitative polymerase chain reaction analysis. On comparison of the CRC primary tumor and matched adjacent normal mucosa (ANM) tissue samples, the mRNA expression levels of ErbB3, but not ErbB1, were significantly increased in CRC tissue samples, compared with those in the ANM tissues. The expression levels of the ligands exhibited opposing trends to their corresponding receptors, including EGF, BTC, AREG, EREG and HB-EGF, which were increased in the CRC tissues, whereas NRG1 and NGR2 were decreased in thee CRC tissues, compared with those in the AMN tissues. Subsequently, the present study
\end{abstract}

Correspondence to: Dr Ryuji Suzuki, Department of Rheumatology and Clinical Immunology, Clinical Research Center for Rheumatology and Allergy, Sagamihara National Hospital, National Hospital Organization, 18-1 Sakuradai, Minami-ku, Sagamihara, Kanagawa 252-0392, Japan

E-mail: r-suzuki@sagamihara-hosp.gr.jp

Abbreviations: CRC, colorectal cancer; ANM, adjacent normal mucosa; EGFR, epidermal growth factor receptor; RT-qPCR, reverse transcription-quantitative polymerase chain reaction; EGF, epidermal growth factor; TGF- $\alpha$, transforming growth factor- $\alpha$; BTC, betacellulin; AREG, amphiregulin; EREG, epiregulin; HB-EGF, heparin-binding-EGF-like growth factor; NRG, neuregulin; GAPDH, glyceraldehyde-3-phosphate dehydrogenase; HPRT, hypoxanthine phosphoribosyl transferase; ACTB, $\beta$-actin

Key words: colorectal cancer, adjacent normal mucosa, epidermal growth factor receptor, epidermal growth factor receptor ligands, reverse transcription-quantitative polymerase chain reaction, K-ras investigated the frequency of K-ras mutations in the patients with CRC. The K-ras mutations were found to be present in $36.8 \%(45 / 122)$ of the cases, however, no correlation was observed between K-ras mutations and clinicopathological characteristics. In the CRC tissues, the expression levels of the EGFR family receptors and their ligands were determined in wild-type and mutant K-ras CRC cases. The expression levels of ErbB1, ErbB2, ErbB3, BTC, AREG, EREG, NRG1 and NRG2 were significantly decreased in the mutant K-ras cases, compared with those in the wild-type K-ras cases. These results suggested that the tumorigenesis of CRC with wild-type K-ras was mediated through, not only ErbB1, but also through the ErbB2 and ErbB3 pathways. Notably, although ErbB2 does not bind any ErbB ligands, ErbB2 may activate tumorigenesis via a heterodimer, rather than a homodimer. Therefore, the results of the present study suggest that the most effective strategy to target not only ErbB1, but also ErbB2 and ErbB3, is the use of monoclonal antibody treatment.

\section{Introduction}

Colorectal cancer (CRC) is one of the most commonly diagnose types of cancer worldwide, and accounts for $\sim 9.4 \%$ of all malignancies (1). The most effective treatment for CRC is surgery, however, $\sim 60 \%$ of patients who undergo curative resection experience local recurrence or distant metastasis (2). Despite advances in surgical techniques and chemotherapeutic options, the survival rate of patients with CRC has not improved substantially, and $20 \%$ of patients with CRC succumb to mortality from recurrence of the disease (3). Thus, novel and effective treatments are required to treat CRC. Among adjuvant therapies, chemotherapy, including the use of oxaliplatin, fluorouracil and leucovorin, has been an efficient strategy, however, it remains incapable of preventing recurrence in all patients (4). Therefore, targeting tumor-associated proteins and inhibiting essential processes of the tumor are being extensively investigated. 
The proto-oncogene referred to as epidermal growth factor receptor (EGFR) is a well-known tyrosine kinase growth factor receptor (5). The EGFR family includes four distinct receptors: HER1/EGFR/ErbB1, HER2/ErbB2, HER3/ErbB3, and HER4/ErbB4, and their eight ligands: Epidermal growth factor (EGF), transforming growth factor- $\alpha$ (TGF- $\alpha)$, betacellulin (BTC), amphiregulin (AREG), epiregulin (EREG), heparin-binding-EGF-like growth factor (HB-EGF), neuregulin (NRG1) and NRG2 (5). Binding of a ligand to its receptor and the subsequent receptor hetero- and homo-dimerization leads to a phosphorylation cascade mediated via tyrosine kinases (5). Therefore, in addition to conventional treatments, EGFR family-targeted monoclonal antibodies have been used to treat patients with CRC.

Cetuximab and panitumumab, which are anti-ErbB1 monoclonal antibodies, are widely used in the treatment of CRC (6-8). However, only $20 \%$ of patients respond to anti-ErbB1 monotherapy (9).

$\mathrm{K}$-ras is one of the downstream signaling molecules of the EGFR family, and is one of the most frequently mutated oncogenes, with K-ras mutations frequently found in various types of tumor (10). Furthermore, upon K-ras mutation, its downstream signaling pathway operates independently of the EGFR family and its signaling activation by ligands (11). The search for predictive markers to improve clinical outcomes has identified that the presence of a K-ras mutation predicts an adverse response, which has led to routine K-ras assessments prior to anti-ErbB1 therapy (11). However, K-ras mutations are present in only $30-40 \%$ of CRC tumors, and a significant proportion of wild-type K-ras patients (50-65\%) do not respond to anti-ErbB1 therapy (9). In addition, treatments for targets other than ErbB1 are not yet available for CRC. ErbB2 is targeted by the monoclonal antibody trastuzumab (Herceptin $^{\mathrm{TM}}$ ) in breast cancer $(12,13)$, and therapeutic agents targeting ErbB3, including MM-121, AMG 888, TK-A3, and TK-A4 are available, however, they are not used clinically (14). A detailed evaluation, describing the synchronous modulation of expression between EGFR family receptors and their ligands, in terms of K-ras mutations in CRC tissues, has not been reported.

Therefore, in the present study, the expression profiles of the four EGFR family genes and their eight ligands were examined in CRC tissues and in adjacent normal mucosa (ANM) tissues from 122 patients using reverse transcription-quantitative polymerase chain reaction (RT-qPCR) analysis. Furthermore, $\mathrm{K}$-ras gene mutations in CRC tissues were investigated, and the expression of EGFR family genes and their ligands were compared between cases of CRC exhibiting wild-type and mutant K-ras.

\section{Materials and methods}

Patients and samples. Tissue specimens were obtained from 122 patients (60 males and 62 females; 30-91 years old) who underwent resections for CRC at Sagamihara National Hospital (Sagamihara, Japan) between 2010 and 2013 (Table I). As control samples, resected specimens $\left(5 \mathrm{~mm}^{3}\right)$ were obtained from the ANM at the margin of the CRC primary tumor $(\geq 10 \mathrm{~cm}$ distance from the tumor). All specimens were confirmed as ANM or CRC by a pathologist. The ANM specimens were further confirmed to be free of cancer cells by the pathologist. The diameters of the primary tumors, numbers of lymph nodes with metastases and development of distant metastases were classified according to the Union for International Cancer Control TNM staging system (15). The study procedures were approved by the Research Ethical Committee of Sagamihara Hospital (Sagamihara, Japan). Informed consent for the present study was obtained from all patients and the patient's families prior to commencement.

Preparation of tissue specimens. Following surgery or biopsy, half of the ANM and CRC specimens were immediately soaked in RNAlater ${ }^{\circledR}$ RNA Stabilization Reagent (Qiagen, Hilden, Germany) and stored at $-80^{\circ} \mathrm{C}$ until performing RNA extraction. The other half were used for pathological examinations.

RNA extraction and cDNA synthesis. The ANM and CRC specimens were homogenized in QIAzol Lysis reagent with homogenizer beads (Qiagen) using a vortex-type homogenizer (Shakeman 2; BioMedical Science, Co., Ltd., Tokyo, Japan). Total RNA was extracted using an RNeasy ${ }^{\circledR}$ Lipid Tissue kit (Qiagen). The quality and concentration of total RNA were validated using an Agilent 2100 Bioanalyzer (Agilent Technologies, Inc., Santa Clara, CA, USA). The freshly isolated total RNA from the ANM and CRC tissues was converted into cDNA using a PrimeScript ${ }^{\mathrm{TM}}$ RT Reagent kit (Takara Bio, Inc., Otsu, Japan), according to the manufacturer's instructions.

$R T$-qPCR. RT-q-PCR was performed using a Bio-Rad CFX96 system (Bio-Rad Laboratories, Inc., Hercules, CA, USA) according to the manufacturer's instructions. The thermal cycling conditions were $30 \mathrm{sec}$ at $95^{\circ} \mathrm{C}$ for one cycle, 50 cycles of $1 \mathrm{sec}$ at $95^{\circ} \mathrm{C}$ and $5 \mathrm{sec}$ at $60^{\circ} \mathrm{C}$ using the Bio-Rad CFX96 system (Bio-Rad Laboratories, Inc.). Results were normalized to the expression of $\beta$-actin (ACTB) and the absolute copy numbers of unknown samples were calculated by comparing the threshold cycles with the corresponding standard curve, based on the $\Delta \Delta \mathrm{Cq}$ method (16). Specific primers for the EGFR family members (ErbB1, ErbB2, ErbB3 and ErbB4), EGFR ligands (EGF, TGF- $\alpha$, BTC, AREG, EREG, HB-EGF, NRG1 and NRG2) and housekeeping genes (HKGs), including glyceraldehyde-3-phosphate dehydrogenase (GAPDH), hypoxanthine phosphoribosyltransferase (HPRT) and ACTB were purchased from Takara Bio, Inc. (Table II).

The amplified products were cloned into the pGEM $^{\circledR}$-T Easy Vector system (Promega Corporation, Madison, WI, USA). The same plasmid was linearized by enzymatic digestion at $37^{\circ} \mathrm{C}$ for $2 \mathrm{~h}$ (Not I; Takara Bio, Inc.) and used as a quantification standard. The sequences were confirmed by DNA sequencing using a CEQ8000 Genetic Analysis System (Beckman Coulter, Fullerton, CA, USA). The quality and concentration of the quantification standard were validated using the Agilent 2100 Bioanalyzer. The qPCR reaction mixture consisted of $5 \mu \mathrm{l}$ SsoFast ${ }^{\mathrm{TM}}$ EvaGreen ${ }^{\circledR}$ Supermix (Bio-Rad Laboratories, Inc.), $3.5 \mu \mathrm{l}$ RNase/DNase-free water, $0.5 \mu \mathrm{l} 5 \mu \mathrm{M}$ primer mix and $1 \mu \mathrm{l}$ cDNA in a final volume of $10 \mu \mathrm{l}$. The cycle number for RT-qPCR was 50. All experiments were performed in duplicate.

Genomic DNA extraction and K-ras mutation analysis. Genomic DNA was extracted from $500 \mathrm{mg}$ of the samples 
Table I. Clinicopathological characteristics and percentages of K-ras mutations in patients with CRC.

\begin{tabular}{|c|c|c|c|}
\hline $\begin{array}{l}\text { Clinicopathological } \\
\text { characteristic }\end{array}$ & $\begin{array}{l}\text { Number of } \\
\text { patients }(\%)\end{array}$ & $\begin{array}{c}\text { Patients with } \\
\text { wild-type K-ras } \\
\text { CRC }(\%)\end{array}$ & $\begin{array}{c}\text { Patients with } \\
\text { mutant K-ras } \\
\text { CRC }(\%)\end{array}$ \\
\hline Total cases & $122(100.0)$ & $77(63.2)$ & $45(36.8)$ \\
\hline \multicolumn{4}{|l|}{ Gender } \\
\hline Male & $60(49.2)$ & $42(70.0)$ & $18(30.0)$ \\
\hline Female & $62(50.8)$ & $35(56.5)$ & $27(43.5)$ \\
\hline \multicolumn{4}{|l|}{ Age (years) } \\
\hline$<65$ & 35 (28.7) & $22(62.9)$ & $13(37.1)$ \\
\hline$\geq 65$ & $87(71.3)$ & $55(63.2)$ & $32(36.8)$ \\
\hline \multicolumn{4}{|l|}{ Site of tumor } \\
\hline Rectum & $27(22.1)$ & $17(63.0)$ & $10(37.0)$ \\
\hline Sigmoid colon & $37(30.3)$ & $24(64.9)$ & $13(35.1)$ \\
\hline Descending colon & $8(6.6)$ & $6(75.0)$ & $2(25.0)$ \\
\hline Transverse colon & $11(9.0)$ & $9(81.8)$ & $2(18.2)$ \\
\hline Ascending colon & $30(24.6)$ & $16(53.3)$ & $14(46.7)$ \\
\hline Cecum & $9(7.4)$ & $5(55.6)$ & $4(44.4)$ \\
\hline \multicolumn{4}{|l|}{ T stage } \\
\hline $\mathrm{pT} 1 / \mathrm{T} 2$ & $18(14.8)$ & $10(55.6)$ & $8(44.4)$ \\
\hline $\mathrm{pT} 3 / \mathrm{T} 4$ & $104(85.2)$ & $67(64.4)$ & $37(35.6)$ \\
\hline \multicolumn{4}{|l|}{$\mathrm{N}$ stage } \\
\hline $\mathrm{pN} 0$ & $51(41.8)$ & $37(72.5)$ & $14(27.5)$ \\
\hline pN1-3 & $71(58.2)$ & $40(56.3)$ & $31(43.7)$ \\
\hline \multicolumn{4}{|l|}{ M stage } \\
\hline M0 & $103(84.4)$ & $64(62.1)$ & 39 (37.9) \\
\hline M1 & $19(15.6)$ & $13(68.4)$ & $6(31.6)$ \\
\hline \multicolumn{4}{|l|}{ Clinical stage } \\
\hline I & $13(10.7)$ & $9(69.2)$ & $4(30.8)$ \\
\hline II & $38(31.1)$ & $28(73.7)$ & $10(26.3)$ \\
\hline III & $52(42.6)$ & 27 (51.9) & $25(48.1)$ \\
\hline IV & $19(15.6)$ & $13(68.4)$ & $6(31.6)$ \\
\hline
\end{tabular}

CRC, colorectal cancer; T stage, primary tumor diameter; N stage, number of lymph nodes; M stage, metastasis.

using a Quick Gene DNA tissue kit (Kurabo, Osaka, Japan). Mutations in K-ras codons 12 and 13 were detected using a multiplex PCR-Luminex method-based MEBGEN Mutation kit (Medical and Biological Laboratories, Nagoya, Japan) according to the manufacturer's instructions.

Statistical analyses. To compare expression levels in the ANM and CRC tissues, Mann-Whitney U and Wilcoxon signed-rank tests were used. All statistical analyses were performed using Prism5 for Windows (GraphPad Software, Inc, San Diego, CA, USA). Data are presented as the mean values. $\mathrm{P}<0.05$ was considered to indicate a statistically significant difference.

\section{Results}

Selection of appropriate HKGs in ANM and CRC tissues. The present investigated the mRNA levels of three HKGs in the ANM and CRC tissues using RT-qPCR (Table III). The copy numbers in the experiments were compared using $1 \mu \mathrm{g}$ total RNA. The mRNA expression levels of ACTB were similar in the ANM and CRC tissues $(\mathrm{P}=0.957)$. By contrast, the mRNA expression levels of GAPDH and HPRT were significantly increased in the CRC tissues, compared with those in the ANM tissues $(\mathrm{P}<0.001)$. Therefore, ACTB was selected as the internal standard gene in the present study. The calculated copy numbers were normalized based on the copy numbers of ACTB.

Gene expression profiles of EGFR family members and their ligands in ANM and CRC tissues. The present study determined the mRNA expression levels of EGFR family members and their ligands in the ANM and CRC tissues using RT-qPCR (Fig. 1). Among the EGFR family members, the mRNA level of ErbB2 was the highest (Fig. 1A). The mRNA expression levels of ErbB1 and ErbB3 were approximately half of the mRNA expression level of ErbB2. In addition, low expression 
Table II. Primer sequences used for reverse transcription-quantitative polymerase chain reaction analysis.

\begin{tabular}{lll}
\hline Target & \multicolumn{1}{c}{ Forward primer $\left(5^{\prime}-3^{\prime}\right)$} & \multicolumn{1}{c}{ Reverse primer $\left(5^{\prime}-3^{\prime}\right)$} \\
\hline GAPDH & GCACCGTCAAGGCTGAGAAC & ATGGTGGTGAAGACGCCAGT \\
HPRT & GGCAGTATAATCCAAAGATGGTCAA & GTCAAGGGCATATCCTACAACAAAC \\
ACTB & TGGCACCCAGCACAATGAA & CTAAGTCATAGTCCGCCTAGAAGCA \\
ErbB1 & GGTGCGAATGACAGTAGCATTATGA & AAAGGTGGGCTCCTAACTAGCTGAA \\
ErbB2 & CAGGCACCGCAGCTCATCTA & TCCCAGGTCACCATCAAATACATC \\
ErbB3 & CCCAGCATCTGAGCAAGGGTA & TTTAGGCGGGCATAATGGACA \\
ErbB4 & TGATAGGCCGTTGGTTGTCTGA & CCAGGTAGACATACCCAATCCAGTG \\
EGF & CAACCAGTGGCTGGTGAGGA & GAGCCCTTATCACTGGATACTGGAA \\
TGF- $\alpha$ & AGATAGACAGCAGCCAACCCTGA & CTAGGGCCATTCTGCCCATC \\
BTC & CTTCACTGTGTGGTGGCAGATG & ATGCAGTAATGCTTGTATTGCTTGG \\
AREG & GTGGTGCTGTCGCTCTTGATACTC & TCAAATCCATCAGCACTGTGGTC \\
EREG & GTGATTCCATCATGTATCCCAGGAG & AGATGCACTGTCCATGCAAACAA \\
HB-EGF & GGGCATGACTAATTCCCACTGA & GCCCAATCCTAGACGGCAAC \\
NRG1 & TCGGTGTGAAACCAGTTCTGAATA & TCTCCAGAATCAGCCAGTGATG \\
NRG2 & ACCCTAGGCTTGGAGCTGGA & CCATTCGGGTAGCTGTGTCTTTATC
\end{tabular}

GAPDH, glyceraldehyde-3-phosphate dehydrogenase; HPRT, hypoxanthine phosphoribosyl transferase; ACTB, $\beta$-actin; EGF, epidermal growth factor; TGF- $\alpha$, transforming growth factor- $\alpha$; BTC, betacellulin; AREG, amphiregulin; EREG, epiregulin; HB-EGF, heparin-binding-EGF-like growth factor; NRG, neuregulin.

Table III. Comparisons of the expression levels of HKGs between ANM and CRC tissues.

\begin{tabular}{lccr}
\hline HKG & ANM & CRC & P-value \\
\hline GAPDH $\left(\times 10^{6}\right)$ & $11.4 \pm 3.46$ & $21.1 \pm 4.30$ & $<0.001$ \\
HPRT $\left(\times 10^{4}\right)$ & $28.7 \pm 7.48$ & $76.7 \pm 1.91$ & $<0.001$ \\
ACTB $\left(\times 10^{6}\right)$ & $19.7 \pm 8.91$ & $20.3 \pm 8.29$ & 0.957 \\
\hline
\end{tabular}

Data are presented as the mean \pm standard deviation. P-values were determined using the Wilcoxon matched-pairs signed rank test. HKG, housekeeping gene; ANM, adjacent normal mucosa; CRC, colorectal cancer; GAPDH, glyceraldehyde-3-phosphate dehydrogenase; HPRT, hypoxanthine phosphoribosyl transferase; ACTB, $\beta$-actin.

levels of ErbB4 were observed in the CRC and ANM tissues. The mRNA expression levels of ErbB3 were significantly increased in the CRC tissues, compared with those in the ANM tissues $(\mathrm{P}<0.005)$, whereas the mRNA expression levels of ErbB1 were significantly decreased in the CRC tissues, compared with those in the ANM tissues $(\mathrm{P}<0.005)$. No significant differences were observed in the expression levels of ErbB2 and ErbB4 between the ANM and CRC tissues.

Among the EGFR family ligands, the mRNA expression levels of EGF, BTC, AREG, EREG and HB-EGF were significantly increased in the CRC tissues, compared with those in the ANM tissues $(\mathrm{P}<0.005, \mathrm{P}<0.05, \mathrm{P}<0.001, \mathrm{P}<0.001$ and $\mathrm{P}<0.001$, respectively), and the mRNA expression levels of NRG1 and NRG2 were significantly decreased in the CRC tissues, compared with those in the ANM tissues $(\mathrm{P}<0.001$; Fig. 1B). However, no difference was observed in the expression levels of TGF- $\alpha$ between the ANM and CRC tissues.
Detection of $K$-ras mutations in CRC tissues. The present study subsequently evaluated the genomic DNA from the tumor specimens for mutations in the K-ras gene (Table I). Mutations in K-ras codons 12 and 13 were detected in 45 of the $122(36.8 \%)$ samples. Comparisons of the K-ras mutations and clinicopathological characteristics revealed that the mutation rate was higher in females than in males. In terms of the tumor site, K-ras mutation rates were higher in the ascending colon and cecum, and lower in the descending colon and transverse colon. The $\mathrm{pT} 1 / \mathrm{T} 2 \mathrm{~T}$ stage, $\mathrm{pN1}-3 \mathrm{~N}$ stage and clinical stage III groups exhibited K-ras mutation rates of $>40 \%$.

Gene expression profiles of EGFR family members and their ligands in CRC tissues with wild-type and mutant $K$-ras. The present study determined the mRNA expression levels of EGFR family members and their ligands in CRC tissues exhibiting wild-type or mutant K-ras using RT-qPCR (Fig. 2). The mRNA expression levels of ErbB1, ErbB2 and ErbB3, but not ErbB4, were significantly decreased in the mutant K-ras group, compared with those in the wild-type K-ras group $(\mathrm{P}<0.05$; Fig. 2A). Notably, the expression levels of the ErbB1-binding ligands (BTC, AREG and EREG) and ErbB3-binding ligands (NRG1 and NRG2) were significantly decreased in the mutant K-ras group, compared with those in the wild-type K-ras group $(\mathrm{P}<0.05, \mathrm{P}<0.005, \mathrm{P}<0.005, \mathrm{P}<0.005$ and $\mathrm{P}<0.05$, respectively; Fig. 2B). By contrast, no significant differences in the expression levels of EGF, TGF- $\alpha$ or HB-EGF were observed between the mutant and wild-type K-ras groups.

\section{Discussion}

In the present study, the mRNA expression levels of the four EGFR family members and their eight ligands were analyzed 
A

ErbB1

ErbB2

B

EGF

TGF- $\alpha$

BTC

AREG
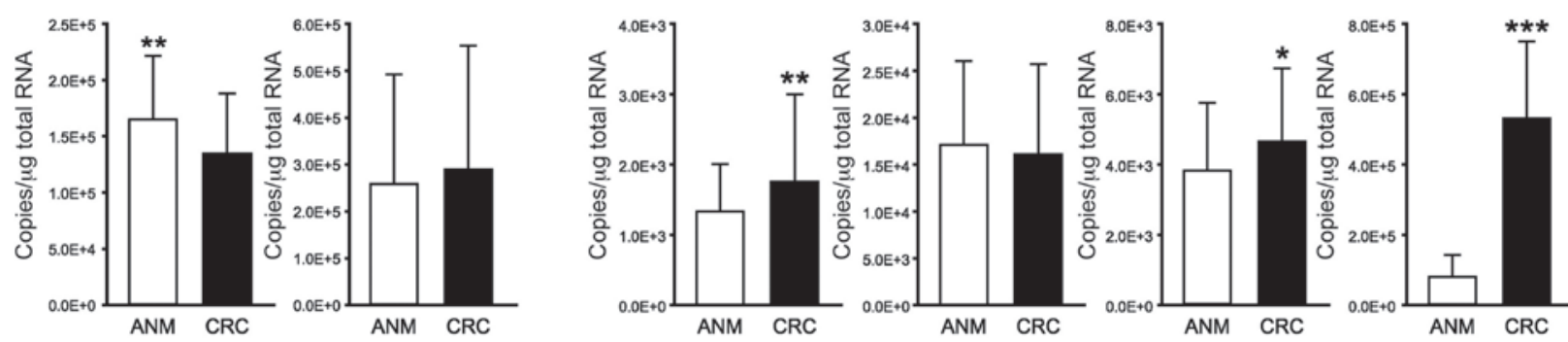

ErbB3

ErbB4

EREG

HB-EGF

NRG1

NRG2
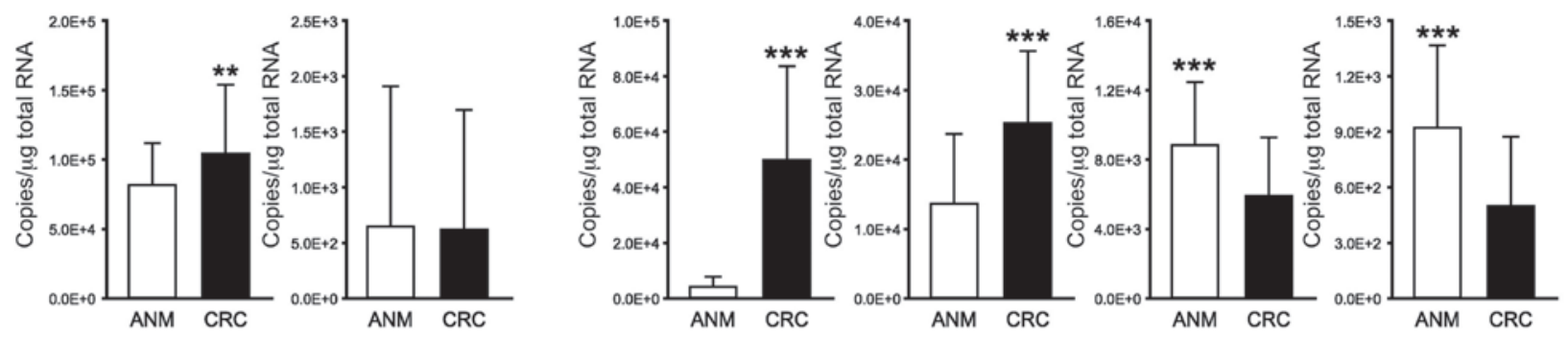

Figure 1. Gene expression profiles of EGFR family members and their ligands in ANM and CRC tissues. mRNA expression levels of (A) EGFR family members and their (B) ligands in ANM and CRC tissues were examined using reverse transcription-quantitative polymerase chain reaction. The ACTB gene was used as an internal control. All experiments were performed in duplicate. Data are presented as the mean \pm standard deviation $(\mathrm{n}=122)$. ${ }^{*} \mathrm{P}<0.05,{ }^{* *} \mathrm{P}<0.005$ and ${ }^{* * *} \mathrm{P}<0.001$ (Wilcoxon signed-rank test). (A) mRNA levels of ErbB3 were significantly increased in CRC tissues, compared with ANM tissues, whereas mRNA expression levels of ErbB1 were significantly decreased in CRC tissues, compared with those in ANM tissues. The mRNA expression level of ErbB2 exhibited the highest level of expression among the EGFR family members in the ANM and CRC tissues. (B) mRNA expression levels of EGF, BTC, AREG, EREG and HB-EGF were increased significantly in the CRC tissues, compared with those in the ANM tissues, whereas the mRNA expression levels of NRG1 and NRG2 were decreased significantly in the CRC tissues, compared with those in the ANM tissues. EGFR, epidermal growth factor receptor; ANM, adjacent normal mucosa; CRC, colorectal cancer; EGF, epidermal growth factor; TGF- $\alpha$, transforming growth factor- $\alpha$; BTC, betacellulin; AREG, amphiregulin; EREG, epiregulin; HB-EGF, heparin-binding-EGF-like growth factor; NRG, neuregulin.

A

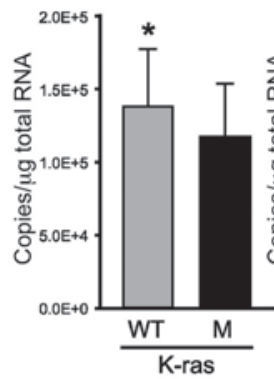

ErbB3

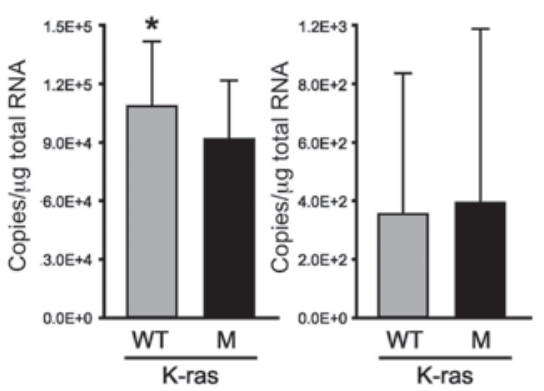

ErbB2

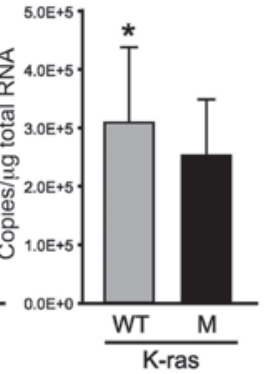

ErbB4

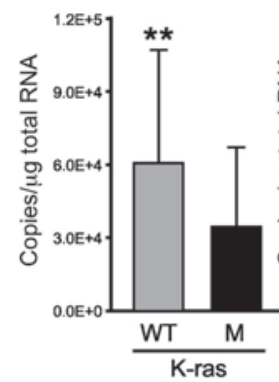

TGF-a

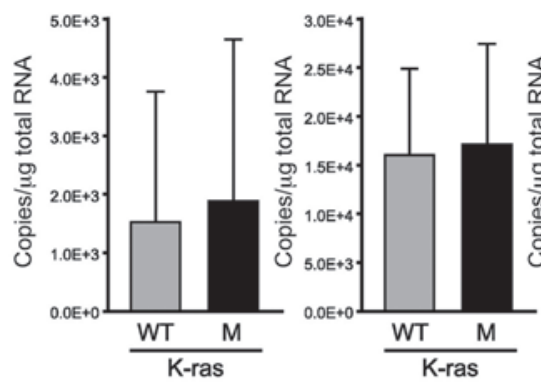

HB-EGF
BTC

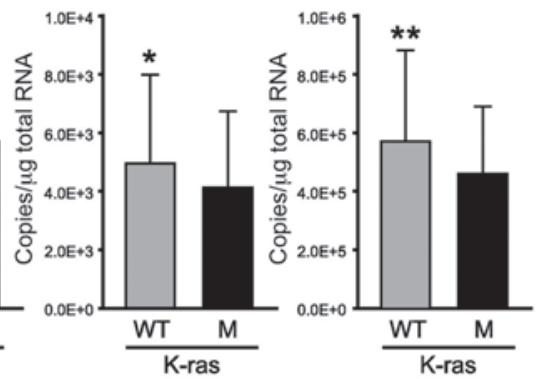

NRG1
NRG2
AREG
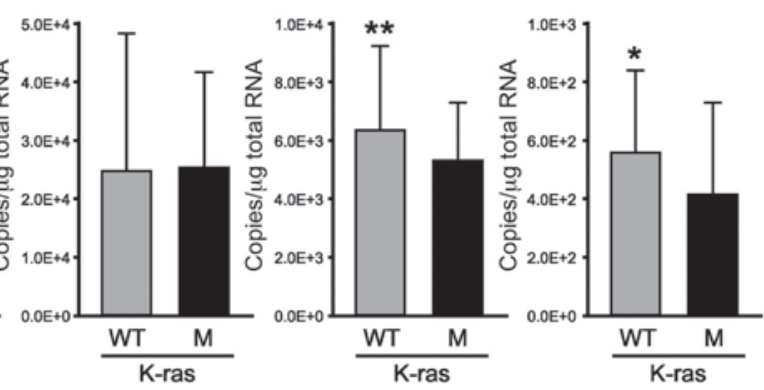

Figure 2. Gene expression profiles of EGFR family members and their ligands in CRC tissues with wild-type or mutant K-Ras. In the colorectal cancer tissues, the mRNA expression levels of (A) EGFR family members and their (B) ligands in the wild-type K-ras (gray; n=77) and mutant K-ras group (black; n=45) were measured using reverse transcription-quantitative polymerase chain reaction. The ACTB gene was used as an internal control. All experiments were performed in duplicate. Data are presented as the mean \pm standard deviation. ${ }^{*} \mathrm{P}<0.05$ and ${ }^{* *} \mathrm{P}<0.005$ (Mann-Whitney U-test). (A) Expression levels of ErbB1, ErbB2 and ErbB3 were significantly decreased in the mutant K-ras group, compared with the wild-type K-ras group. (B) Expression levels of the ErbB1-binding ligands (BTC, AREG and EREG) and ErbB3-binding ligands (NRG1 and NRG2) were significantly decreased in the mutant K-ras group, compared with the wild-type K-ras group. EGFR, epidermal growth factor receptor; EGF, epidermal growth factor; TGF- $\alpha$, transforming growth factor- $\alpha$; BTC, betacellulin; AREG, amphiregulin; EREG, epiregulin; HB-EGF, heparin-binding-EGF-like growth factor; NRG, neuregulin; WT, wild-type; M, mutant. 
in tissue specimens from 122 patients with CRC using RT-qPCR. To perform accurate analyses, the present study first compared the mRNA levels of three HKGs (GAPDH, HPRT and ACTB), between the ANM and CRC tissues. Certain studies have reported that the expression levels of HKGs under hypoxic conditions vary widely (17-19). Zhong and Simons reported that mRNA expression levels of GAPDH in cell lines are increased by 21.2-75.1\% under hypoxic conditions (20). In HKG comparison study of a large panel of cancer types, HPRT was suggested as the single optimal reference gene (21). Another report suggested that ACTB is the most stable gene in diabetic glomeruli and primary mesangial cells (22). In the present study, the expression levels of ACTB were almost equal in the ANM and CRC tissues. However, compared with the ANM tissues, $>2$-fold increases in the expression levels of GAPDH and HPRT were observed in the CRC tissues. Therefore, these results suggested that ACTB was the most suitable HKG for the analyses of patients with CRC in the presnt study.

Overexpression of EGFR family members has been associated with malignant transformation, as well as poor clinical outcomes in CRC (23). ErbB1 is overexpressed in patients with CRC (24), and high expression levels of ErbB3 have been observed in $70 \%$ of primary CRC tumors (25). In the present study, the mRNA expression levels of ErbB3 were significantly increased in CRC tissues, compared with those in ANM tissues, whereas the mRNA expression levels of ErbB1 were significantly decreased in CRC tissues, compared with those in ANM tissues. Koenders et al reported similar results of low expression levels of ErbB1 in CRC tissues, and concluded that the lower ErbB1 content in CRC is caused by downregulation of the receptor by a locally produced ligand (26). In the present study, the expression levels of the EGFR ligands exhibited opposing trends to their corresponding receptors, including EGF, BTC, AREG, EREG and HB-EGF, which were increased, and NRG1 and NRG2, which were decreased in the CRC tissues, compared with those in the AMN tissues. Taken together, the expression levels of EGFR family members and their ligands were altered between the ANM and CRC tissues.

To perform a detailed evaluation of the expression of EGFR in CRC, determination of K-ras gene mutations is important, as mutation of K-ras leads to the downstream signaling pathway operating independently of the EGFR family and its signaling activation by ligands. Previous studies have concluded that K-ras mutations lead to poor survival rates in patients, particularly following treatment with anti-ErbB1 antibodies and chemotherapy $(27,28)$. Therefore, the present study evaluated genomic DNA from tumor specimens for mutations in the K-ras gene, and compared the findings with the clinicopathological characteristics of the patients to investigate the function of the EGFR family in CRC. In total, 45 mutations $(36.8 \%)$ were found in the 122 samples, including common mutations in codons 12 and 13. In a previous cohort study, 37\% (271/737) of patients with CRC were found to have mutations in codons 12 and 13 in the K-ras gene (29). Taback et al also reported that mutation of the K-ras allele at codons 12 or 13 occurred in $42 \%(30 / 72)$ of paraffin-embedded primary CRC tissues from a cohort of patients (30). Therefore, the incidence of K-ras mutations in the present study was concordant with those reported in previous studies of European and American patients. Comparisons of K-ras mutations with the clinicopathological characteristics revealed that the mutation rate was $>10 \%$ higher at clinical stage III, compared with the total mean. Yunxia et al reported only tumor differentiation as potentially correlated with K-ras mutations (31), whereas another study suggested no correlation with clinicopathological parameters (32). In the present study, although no significant correlation between K-ras mutations and clinicopathological characteristics were identified, further investigations with a larger sample size are required.

Based on the K-ras mutations, the present study analyzed the expression levels of EGFR family members and their ligands in the CRC tissues. With the exception of ErbB4, the expression levels of EGFRs were decreased significantly in the mutant K-ras group, compared with those in the wild-type K-ras group, and the expression pattern of the ligands exhibited a similar trend. These results suggested enhancement of EGFR signaling without the expression of EGFR ligands in the patients with CRC and K-ras mutations. Furthermore, these results indicated that tumorigenesis of CRC with wild-type K-ras was mediated, not only ErbB1, but also by ErbB2 and ErbB3. In particular, although ErbB2 does not bind to any of the ErbB ligands, its expression levels in the present study were different between the wild-type and mutant K-ras groups. Therefore, it is possible that ErbB2 activates tumorigenesis as a heterodimer and not a homodimer. Another report suggested this possibility and found that the ErbB2-ErbB3 heterodimer is the most potent ErbB pair, with respect to the strength of the interaction, ligand-induced tyrosine phosphorylation and downstream signaling, and functions as an oncogenic unit $(33,34)$. Using ErbB3 knockdown mice, Lee et al demonstrated that ErbB3 is essential in supporting intestinal tumorigenesis, and suggested that ErbB3 may be a promising target for the treatment of CRC (35). Trastuzumab is already used for the treatment of ErbB2-overexpressing breast cancer, which binds to a ErbB2 region that is not involved with receptor dimerization (36). However, clinical application has not been assessed in CRC patients due to the lack of clinical proof-of-concept (14). The results of the present study suggested that the most effective strategy to specifically target ErbB1, and also ErbB2 and ErbB3 is monoclonal antibody treatment.

In conclusion, the present study analyzed the expression profiles of the four EGFR family members and their eight ligands in ANM and CRC tissues of 122 patients using RT-qPCR. In addition, K-ras mutation analyses were performed. The results demonstrated that the expression levels of ErbB1, ErbB2, ErbB3, BTC, AREG, EREG, NRG1 and NRG2 were significantly decreased in the mutant K-ras group, compared with those in the wild-type K-ras group. Therefore, the results suggested that the enhancement of tumorigenesis was activated not only by ErbB1, but also by ErbB2 and ErbB3. The mRNA expression levels of ErbB3 were significantly increased in the $\mathrm{CRC}$ tissues, compared with those in the ANM tissues, whereas those of ErbB1 were significantly decreased in the CRC tissues, compared with those in the ANM tissues. Together these observations likely suggest that all ErbB2, ErbB3 and ErbB1 could be potential targets for the treatment of CRC. 


\section{Acknowledgements}

This study was supported by Chugai Pharmaceutical Co., Ltd. (Toyko, Japan), Takeda Pharmaceutical Co., Ltd. (Osaka, Japan) and Yenxakult Honsha Co., Ltd. (Tokyo, Japan).

\section{References}

1. Siegel R, Ma J, Zou Z and Jemal A: Cancer statistics 2014. CA Cancer J Clin 64: 9-29, 2014.

2. Andre N and Schmiegel W: Chemoradiotherapy for colorectal cancer. Gut 54: 1194-1202, 2005.

3. Jemal A, Siegel R, Ward E, Hao Y, Xu J and Thun MJ: Cancer statistics, 2009. CA Cancer J Clin 59: 225-249, 2009.

4. André T, Boni C, Mounedji-Boudiaf L, Navarro M, Tabernero J, Hickish T, Topham C, Zaninelli M, Clingan P, Bridgewater J, et al: Oxaliplatin, fluorouracil, and leucovorin as adjuvant treatment for colon cancer. N Engl J Med 350 2343-2351, 2004.

5. Carpenter G and Cohen S: Epidermal growth factor. J Biol Chem 265: 7709-7712, 1990.

6. Douillard JY, Siena S, Cassidy J, Tabernero J, Burkes R, Barugel M, Humblet Y, Bodoky G, Cunningham D Jassem J, et al: Randomized, phase III trial of panitumumab with infusional fluorouracil, leucovorin and oxaliplatin (FOLFOX4) versus FOLFOX4 alone as first-line treatment in patients with previously untreated metastatic colorectal cancer: The PRIME study. J Clin Oncol 28: 4697-4705, 2010.

7. Lacouture ME, Mitchell EP, Piperdi B, Pillai MV, Shearer H, Iannotti N, Xu F and Yassine M: Skin toxicity evaluation protocol with panitumumab (STEPP), a phase II, open-label, randomized trial evaluating the impact of a pre-emptive skin treatment regimen on skin toxicities and quality of life in patients with metastatic colorectal cancer. J Clin Oncol 28: 1351-1357, 2010.

8. Peeters M, Price TJ, Cervantes A, Sobrero AF, Ducreux M, Hotko Y, André T, Chan E, Lordick F, Punt CJ, et al: Randomized phase III study of panitumumab with fluorouracil, leucovorin and irinotecan (FOLFIRI) compared with FOLFIRI alone as second-line treatment in patients with metastatic colorectal cancer. J Clin Oncol 28: 4706-4713, 2010.

9. De Roock W, De Vriendt V, Normanno N, Ciardiello F and Tejpar S: KRAS, BRAF, PIK3CA and PTEN mutations: Implications for targeted therapies in metastatic colorectal cancer. Lancet Oncol 12: 594-603, 2011.

10. Adjei AA: K-ras as a target for lung cancer therapy. J Thorac Oncol 3 (6 Suppl 2): S160-S163, 2008.

11. Messersmith WA and Ahnen DJ: Targeting EGFR in colorectal cancer. N Engl J Med 359: 1834-1836, 2008

12. Sadeghi S, Olevsky O and Hurvitz SA: Profiling and targeting HER2-positive breast cancer using trastuzumab emtansine. Pharmgenomics Pers Med 7: 329-338, 2014.

13. Shak S: Overview of the trastuzumab (Herceptin) anti-HER2 monoclonal antibody clinical program in HER2-overexpressing metastatic breast cancer. Herceptin multinational investigator study group. Semin Oncol 26 (4 Suppl 12): S71-S77, 1999.

14. Aurisicchio L, Marra E, Roscilli G, Mancini R and Ciliberto G: The promise of anti-ErbB3 monoclonals as new cancer therapeutics. Oncotarget 3: 744-758, 2012.

15. Mehta SP, Jose P, Mirza A, Pritchard SA, Hayden JD and Grabsch HI: Comparison of the prognostic value of the 6th and 7th editions of the Union for International Cancer Control TNM staging system in patients with lower esophageal cancer undergoing neoadjuvant chemotherapy followed by surgery. Dis Esophagus 26: 182-188, 2013.

16. Bustin SA, Benes V, Garson JA, Hellemans J, Huggett J, Kubista M, Mueller R, Nolan T, Pfaffl MW, Shipley GL, et al: The MIQE guidelines: Minimum information for publication of quantitative real-time PCR experiments. Clin Chem 55: 611-622, 2009

17. Caradec J, Sirab N, Keumeugni C, Moutereau S, Chimingqi M, Matar C, Revaud D, Bah M, Manivet P, Conti M and Loric S: 'Desperate house genes': The dramatic example of hypoxia. Br J Cancer 102: 1037-1043, 2010.
18. Schmittgen TD and Zakrajsek BA: Effect of experimental treatment on housekeeping gene expression: Validation by real-time, quantitative RT-PCR. J Biochem Biophys Methods 46: 69-81, 2000.

19. Lupberger J, Kreuzer KA, Baskaynak G, Peters UR, le Coutre P and Schmidt CA: Quantitative analysis of beta-actin, beta-2-microglobulin and porphobilinogen deaminase mRNA and their comparison as control transcripts for RT-PCR. Mol Cell Probes 16: 25-30, 2002.

20. Zhong H and Simons JW: Direct comparison of GAPDH, beta-actin, cyclophilin and $28 \mathrm{~S}$ rRNA as internal standards for quantifying RNA levels under hypoxia. Biochem Biophys Res Commun 259: 523-526, 1999.

21. de Kok JB, Roelofs RW, Giesendorf BA, Pennings JL, Waas ET, Feuth T, Swinkels DW and Span PN: Normalization of gene expression measurements in tumor tissues: Comparison of 13 endogenous control genes. Lab Invest 85: 154-159, 2005.

22. Biederman J, Yee J and Cortes P: Validation of internal control genes for gene expression analysis in diabetic glomerulosclerosis. Kidney Int 66: 2308-2314, 2004.

23. Yarom $\mathrm{N}$ and Jonker DJ: The role of the epidermal growth factor receptor in the mechanism and treatment of colorectal cancer. Discov Med 11: 95-105, 2011.

24. Spano JP, Lagorce C, Atlan D, Milano G, Domont J, Benamouzig R, Attar A, Benichou J, Martin A, Morere JF, et al: Impact of EGFR expression on colorectal cancer patient prognosis and survival. Ann Oncol 16: 102-108, 2005.

25. Lédel F, Hallström M, Ragnhammar P, Öhrling K and Edler D HER3 expression in patients with primary colorectal cancer and corresponding lymph node metastases related to clinical outcome. Eur J Cancer 50: 656-662, 2014.

26. Koenders PG, Peters WH, Wobbes T, Beex LV, Nagengast FM and Benraad TJ: Epidermal growth factor receptor levels are lower in carcinomatous than in normal colorectal tissue. $\mathrm{Br}$ J Cancer 65: 189-192, 1992.

27. Lievre A, Bachet JB, Boige V, Cayre A, Le Corre D, Buc E, Ychou M, Bouché O, Landi B, Louvet $\mathrm{C}$, et al: KRAS mutations as an independent prognostic factor in patients with advanced colorectal cancer treated with cetuximab. J Clin Oncol 26: 374-379, 2008.

28. Andreyev J and Cunningham D: Markers, markers everywhere. Prognosis in colorectal cancer-time for a new approach. J Clin Oncol 19: 286-288, 2001

29. Brink M, de Goeij AF, Weijenberg MP, Roemen GM, Lentjes MH, Pachen MM, Smits KM, de Bruïne AP, Goldbohm RA and van den Brandt PA: K-ras oncogene mutations in sporadic colorectal cancer in the Netherlands cohort study. Carcinogenesis 24: 703-710, 2003.

30. Taback B, Bilchik AJ, Saha S, Nakayama T, Wiese DA, Turner RR, Kuo CT and Hoon DS: Peptide nucleic acid clamp PCR: A novel K-ras mutation detection assay for colorectal cancer micrometastases in lymph nodes. Int J Cancer 111: 409-414, 2004.

31. Yunxia Z, Jun C, Guanshan Z, Yachao L, Xueke Z and Jin L: Mutations in epidermal growth factor receptor and $\mathrm{K}-\mathrm{ras}$ in Chinese patients with colorectal cancer. BMC Med Genet 11: 34, 2010.

32. Bazan V,Migliavacca M,Zanna I, Tubiolo C, Grassi N,Latteri MA, La Farina M, Albanese I, Dardanoni G, Salerno S, et al: Specific codon $13 \mathrm{~K}$-ras mutations are predictive of clinical outcome in colorectal cancer patients, whereas codon $12 \mathrm{~K}$-ras mutations are associated with mucinous histotype. Ann Oncol 13: 1438-1446, 2002.

33. Tzahar E, Waterman H, Chen X, Levkowitz G, Karunagaran D, Lavi S, Ratzkin BJ and Yarden Y: A hierarchical network of interreceptor interactions determines signal transduction by Neu differentiation factor/neuregulin and epidermal growth factor. Mol Cell Biol 16: 5276-5287, 1996.

34. Pinkas-Kramarski R, Soussan L, Waterman H, Levkowitz G, Alroy I, Klapper L, Lavi S, Seger R, Ratzkin BJ, Sela M and Yarden Y: Diversification of Neu differentiation factor and epidermal growth factor signaling by combinatorial receptor interactions. Embo J 15: 2452-2467, 1996.

35. Lee D, Yu M, Lee E, Kim H, Yang Y, Kim K, Pannicia C, Kurie JM and Threadgill DW: Tumor-specific apoptosis caused by deletion of the ERBB3 pseudo-kinase in mouse intestinal epithelium. J Clin Invest 119: 2702-2713, 2009.

36. Cho HS, Mason K, Ramyar KX, Stanley AM, Gabelli SB, Denney DW Jr and Leahy DJ: Structure of the extracellular region of HER2 alone and in complex with the herceptin fab. Nature 421: 756-760, 2003. 